Epoch and Osculation 1904 November 9.0 (M.T. Berlin).

$$
\begin{aligned}
& \mathrm{M}=34^{\circ} \mathbf{1} 33{ }^{\prime \prime} \\
& \pi=\begin{array}{lll}
159 & 2 & 39
\end{array}
\end{aligned}
$$

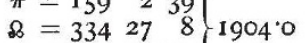

\begin{tabular}{|c|c|c|c|c|c|}
\hline \multicolumn{6}{|c|}{ Ephemeris oh. (M.T. Berlin). } \\
\hline 1904 & & a (app.) & $\delta$ (app.) & $\log r$ & $\log \Delta$ \\
\hline Aug. 13 & $\ldots$ & I 5 I & $+2 \mathrm{I} \quad 10.2$ & 0.3685 & 0.2634 \\
\hline , 17 & $\ldots$ & I 52 I3 & $+2 \mathrm{I} 45^{\circ} \mathrm{O}$ & 0.3615 & 0.2421 \\
\hline $2 \mathrm{I}$ & $\cdots$ & 15257 & +2219.8 & 0.3542 & 0.2201 \\
\hline 25 & $\ldots$ & I 53 I 4 & $+2255^{\circ} \mathrm{I}$ & 0.3467 & 0.1970 \\
\hline, 29 & $\cdots$ & I 5259 & $+2330^{\circ} 4$ & 0.3390 & 0.1732 \\
\hline Sept. $z$ & $\ldots$ & I 529 & $+24 \quad 5 \%$ & 0.3309 & 0.1485 \\
\hline 4 & $\ldots$ & 15 I 28 & +24234 & 0.3268 & $0.135^{\circ}$ \\
\hline , & $\ldots$ & I 5036 & $+244^{\prime \prime} 2$ & 0.3226 & 0.1229 \\
\hline
\end{tabular}

$$
\begin{aligned}
& i=\begin{array}{lll}
12 & 35 & 37
\end{array} \\
& \phi=575420 \\
& \mu=1075^{\prime \prime} \cdot 666 \\
& \log a=0.34555 \\
& \mathrm{~T}=\text { I905 Jan. I Id. } 8 \cdot 8 \mathrm{~h} \text {. M.T. Berlin. }
\end{aligned}
$$

The Revision of the Cape Photographic DurchMUSTERUNG.-In the third volume of the Cape Durchmusterung Sir David Gill referred to several lists of stars which Prof. Kapteyn had prepared in order that the objects might be re-observed and the origins of the discrepancies between the Cape and other catalogues discovered. The work of revision was commenced by Mr. Finlay, but has been continued, since 1896 , by Mr. Innes. Parts i., ii., and iii. of vol. ix. of the Cape Observatory Annals contain the results of this revision, giving the observer's full notes and copious remarks concerning each object observed. Mr. Innes believes that not a single uncoloured star of the ninth magnitude or brighter, and south of declination $-19^{\circ}$, is now missing from the catalogue.

Many of the questionable objects have been found to be variables or highly coloured, whilst others are fainter than the ninth magnitude. Part ii. is especially devoted to full particulars of each variable star observed at the Cape between 1896 and 1902, the elements, the curve, the regioncharts, and all the available information-or references to the same--being given for each of the seventy-three objects observed.

A summary of the number of stars in the C.P.D. exhibits several interesting points. For example, whereas $M$. Stratonoff found that the B.D. (dec. $+90^{\circ}$ to $-20^{\circ}$ ) gave a mean of 4.895 stars brighter than the ninth magnitude for every square degree, the corresponding value in the C.P.D. (dec. $-19^{\circ}$ to $-90^{\circ}$ ) is 5.85 . Part of this difference, at least, may, however, be due to a difference of magnitude standards. The total number of stars now contained in the C.P.D. is $91,35^{8}$, and the richest region is near to $\eta$ Argus, for in the $-59^{\circ}$ zone, between ioh. and $1 \mathrm{Ih}$., there are 256 stars, or 32.7 per square degree, brighter than the ninth magnitude.

Part iii. tabulates, and comments on, the errors found by Prof. Kapteyn-and others discovered since-in other southern star catalogues for the regions south of dec. $-19^{\circ}$, and concludes with a table of reference to all the published errata.

Determination of Latitude and its Variations.-In No. 3962 of the Astronomische Nachrichten M. E. Bijl, of the Royal Belgian Observatory at Uccle, gives the results of 685 determinations of latitude made by him during the period $18984-1899 \cdot 5$. The table given shows the time of each observation and the corresponding latitudes as deduced from the star positions given in the Berliner Jahrbuch and Newcomb's catalogue respectively. There is a constantly positive value for the difference Newcomb-B.J. of something of the order of $+0^{\prime \prime} \cdot 6$. The resulting latitudes show a range of about $\mathrm{O}^{\prime \prime} \cdot 7$ with a maximum at 1888.6 , a minimum at $x 889 \cdot 0$, and a lower maximum at $1889.3-$ I $889 \cdot 4$.

The Standardisation of Rowland's Wave-Lengths.In an article appearing in No. I, vol. xx., of the Astrophysical Journal, Prof. Hartmann answers the criticisms which have been passed on the proposals of his previous article, wherein he strongly urged the standardisation of Rowland's wave-lengths to a uniform relative scale.

NO. I 8 I 5 , VOL. 70] has been urged that Michelson's absolute values should be used for the construction of an absolute scale, but Prof. Hartmann points out that the adoption of this idea would necessitate a wholesale revision each time a new estimate of the absolute wave-lengths was made.

In lieu of this he again suggests that the wave-length of the red line in the cadmium spark spectrum in air at $+20^{\circ} \mathrm{C}$. and $760 \mathrm{~mm}$. pressure be adopted as $\lambda=643869 \mathrm{II}$ for all time, and that a coordination of a system of relative wave-lengths should be made with this as the standard.

The most urgent need before such a system can be completed is that an observer having the control of a large grating spectrograph shall continue Kayser's work in establishing a system of standard iron lines in the region as yet untouched by that observer. This need supplied, the values obtained by Michelson, Hamy, Fabry and Perot for a number of metals would furnish the connecting links for the completion of the proposed system.

Saturn's Ninth Satellite.-From a note by Prof. E. C. Pickering in No. 3962 of the Astronomische Nachrichten, it appears that the position angles and distances of the satellite Phœbe, which were recently published in a Kiel Circular, were obtained from an ephemeris corrected to agree with the positions determined from eleven photographs obtained by Prof. Frost at Arequipa. These allowed the path of the satellite to be followed from April 16 to June 9:

\section{DISTRIBUTION OF SUCCESSES AND OF NATURAL ABILITY AMONG THE KINSFOLK OF FELLOWS OF THE ROYAL SOCIETY.}

THE result of this inquiry is to prove the existence of a small number of more or less isolated hereditary centres, round which a large part of the total ability of the nation is clustered, with a closeness that rapidly diminishes as the distance of kinship from its centre increases.

The materials are derived from the replies to a circular which I sent with a blank schedule, to all fellows of the Royal Society, asking for the names and achievements of their " noteworthy " kinsfolk in each degree of near kinship as specified in the schedule. Noteworthiness was defined as including any success that was, in the opinion of the sender, at least equal in its way to that in which the honour of a fellowship of the Royal Society is held by scientific men.

Returns. are still dropping in, and now exceed two hundred. They continue to be very acceptaßle, but I judged it best to content myself with the number received up to a date when I could conveniently work at them, and to publish preliminary results without longer delay. The total number of returns received up to the date in question, that contained one or more noteworthy kinsfolk, was rio.

Subjoined are classified lists of the qualifications that were considered by one or other of the rio correspondents as warrants of noteworthiness. I attached to each of these more or less noteworthy kinsmen (for my own private use in this inquiry) a $*$, a + , a - or a o, signifying respectively 3,2 , I, or no marks. In doing this, account was taken of honours, of biographical notices, and of the context of the communication, which often helped in deciding cases. Only one of these symbols was allotted to each individual.

$$
\text { A List.-Mostly recipients either of } a * \text { or } a+\text {. }
$$

Ministers of State, Heads of Departmente, Permanent Secretaries, and other high posts in public offices. Member of Parliament, but subject to reservation.

Foreign Ambassador or Minister, Consul General, Secretary of Legation.

Governor of a Colony, Colonial Secretary, high Colonial Office.

Admiral or General in important command. high Staff appointments.

Clerical dignitaries, eminent mini-ters, philanthropists.

Legal dignitaries at hume and in the culonies.

Medical men of distinction.

Professors in great universities, heads of the more important colleges and schrols. University scholarships, first or second place in class lists of universities or in $\mathrm{c}$ mpetitive examinations for Woolwich, Indian Civil, or principal home services.

Distinction in any form of Art-as poet, musician, singer; architect sculptor; painter, engraver, caricaturi $t$; actor.

President or secretary of great institutions connected with science, liserature, art, or purpose of public utility.

Authorship of a standard work, editorship of an important journal, author ship of valuable memoirs.

Inventor in any branch, scirntific traveller. Foundar of a great business, management of great commercial undertakings
pionetr of a new industry. 
$B$ List.-Useful to corroborate and to check.

Honours :-From the Crown-as knighthood and all superior orders. From pub'ic bodies-as honorary university degrees, Fellowship of Royal Society (all F.R.S. were granted a *), of Royal Academy, and uther selected assuciatiuns.

Biographical notices-as in Dictionary of National Biography and in other standard collections. Obituary and other notices in the $j$ urnals of literary and scientific societies. Special memoirs. Men of the time; Who's Who?

\section{List. - Personal estimates taken into account.}

Prominent county man. Active in public affairs, successful in business. Forward in civic matters. Good professional position. Of high repute as a scholar, \&c.

\section{List.-Referring wholly to women.}

A social leader. Great force of character. Reputed very clever. Artistic (in any way) to an exceptional degree. Successful work in educational, civic and philanthropic matters was also taken into account. Brilliant prize winrings at school or college. The folluwing are examples of the mure suggestive returns (but slightly modified). "I have no hesita ion in judging her to be "noteworthy." "Acquisitive mind of a high order." "Learned both Greek and Hebrew unassisted." "Had a great and recognised influence in forming the character of her (di-tinwork."

$E$ List.-Referring to youths only, and reaching at most the qualification of -

Good place in examinations, though lower than the very high ones mentioned above. School scholarships and exhibitions of fair importance.

Much less difficulty was experienced in assigning marks than had been anticipated. The totals of the number given were 183 of $*, 188$ of,+ 83 of -

The $183 *$ included 23 fellows of the Royal Society. Brothers were only counted once.

Abbreviations used in the schedule are employed here also, to distinguish different kinds of kinship that bear the same popular names, as uncles and first cousins. They are convenient, and seem to have been easily understood. They were first suggested by me in Nature of January 28 of this year :-bro=brother ; $d a=$ daughter ; $f a=$ father ; $H u=$ husband ; $m e=$ mother ; $s i=$ sister ; so or $s o n=$ son; $W i=$ wife. fa bro son means " MY father's brother's son IS "; $m e$ da means "MY mother's daughter IS". so Wi bro means "MY son's wife's brother IS," \&c.

The total amount of marks that were thus assigned to each grade of kinship are given in Table I. For example, out of the rio $f a f a f a$ of the rio senders, 3 were allotted a $*, x \mathrm{a}+$, and none $\mathrm{a}-$. Out of the I Io $f a$ the corresponding numbers were $27,25,5$.

TABLE I.-Distribution of Symbols and of Indices of Success among the Kinsfolk of the r ro Senders.

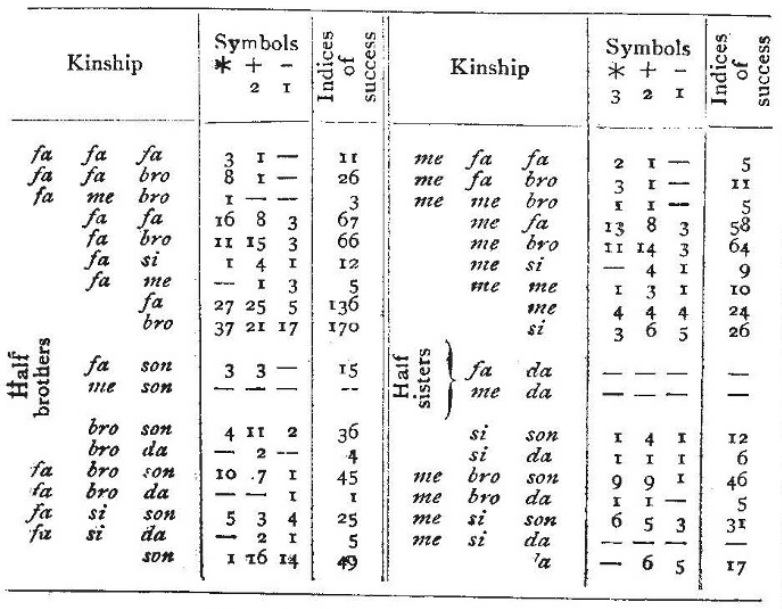

Total $x 83$ of $*, x 88$ of,+ 83 of - .

Examples:- the index for $f a f a f x$ is equal to 3 multiplied into 3 , plus 2 multiplied into $\pi,=9+2,=\pi r$; that for si son is equal to $(\mathrm{r} \times 3$,
$+4 \times 2,4+\times \tau)=3+8+x=\pi 2$.

NO. I $8[5$, VOL. 70$]$
Tables II. and III. are based on Table I.

TABLE II. - Successes of Kinsmen of Feliows of the Royal Society.

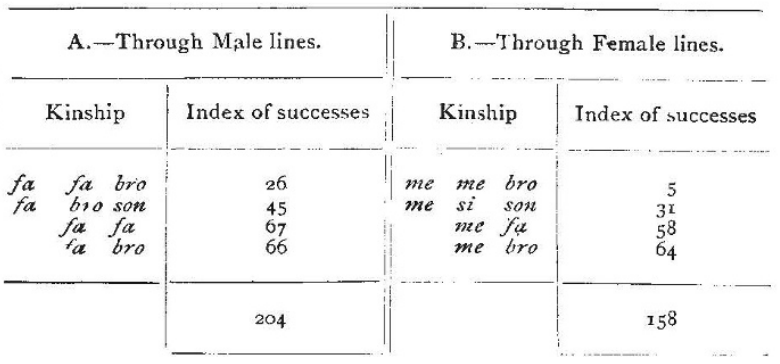

A popular notion that ability is mainly transmitted through female lines is more than contradicted by these figures.

The families of the fellows of the Royal Society must be fertile, because the number of brothers, whether of selves or of fathers, came out closely as 2.43. I will not now pursue the analysis, as the other kinds of kinship are hardly numerous enough in the present collection to justify conclusions.

TABLE III. - Indices of Success among near Kinsmen in Ascending Generations of the $\mathrm{I}$ ro Contributors.

\begin{tabular}{|c|c|c|c|c|c|c|}
\hline \multicolumn{4}{|c|}{ I 10 persons in each class } & \multicolumn{3}{|c|}{$\begin{array}{c}\text { Brothers of } 1 \text { ro persons in } \\
\text { each class }\end{array}$} \\
\hline Generation & Kinship & $\begin{array}{l}\text { Observed } \\
\text { indices }\end{array}$ & $\begin{array}{c}\text { Accepted } \\
\text { indices }\end{array}$ & Kinship & $\begin{array}{l}\text { Observed } \\
\text { indices }\end{array}$ & $\begin{array}{l}\text { Accepted } \\
\text { indices }\end{array}$ \\
\hline I. & Selves & $33^{\circ}$ & $33^{\circ}$ & Brothers & 170 & 170 \\
\hline II. & fathers & 136 & $r_{3} 6$ & $\begin{array}{l}\text { fa bros } \\
\text { me bros }\end{array}$ & $\begin{array}{l}66 \\
64\end{array}$ & 65 \\
\hline III. & $\begin{array}{l}f a f i x \\
\text { me } f a\end{array}$ & $\begin{array}{l}67 \\
58\end{array}$ & 62 & $\begin{array}{l}\text { fa fa bros } \\
\text { ne me bros }\end{array}$ & $\begin{array}{r}26 \\
5\end{array}$ & r6 \\
\hline Additional & $f a f a f a$ & $3 x$ & & fa me bros & $\begin{array}{l}3 \\
5\end{array}$ & \\
\hline
\end{tabular}

Distribution of Success in the Families of Successful Men (from Table III.)

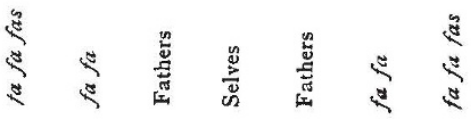

MEAN LEVEL MEAN LEVEL

总

The upper line of the diagram indicates the successes of direct male ancestors, the lower line those of their brothers. The mean level of the community was inferred from the fact that it cannot be higher than the lowest entries in Table III., so far as these are to be trusted, and that these would be of barely perceptible magnitude in the small diagram.

Relation of Success to Natural Ability. -The success of 
a man is wholly due to the combined effect of Natural Gifts and of Circumstances. More, however, being included under the title of natural gifts than can influence success, this part may be disregarded. The remainder comprises intellectual power, appropriate tastes, a persevering disposition, and much else, forming a large group which will be briefly termed "Natural Ability." The Circumstances, so far as they affect success, include healthy rearing, family and social influences, education, money, leisure, and surroundings that encourage work or idleness.

Men whose histories are known can be sorted with rough fairness, and with little difficulty, into three grades of natural ability, one-third of the whole number being classed as "above mediocrity" and marked +1 , another third being classed as "mediocre" and marked o, the remaining third being classed as " below mediocrity " and marked - $\mathrm{I}$. After this has been done and the results recorded, the same men may be sorted afresh and independently into three grades, according to their Circumstances, one-third of them consisting of those whose circumstances conduced to success and are marked $+\mathrm{I}$, the other thirds being respectively marked $o$ and $-I$ on the principle already explained. Assuming for the moment (the question will be discussed later on), first, that Natural Ability and Circumstance are independent, and, secondly, that the mark for Success will always be equal to the sum of those for Ability and Circumstance, then the relation of Success to Ability is easily found. A square table (Table IV.) is made with three columns and three horizontal bands; it consequently contains nine compartments. The "arguments" at the head of the several columns will be $+I, 0,-I$; so will be those that precede the several bands. Then an entry is made in each compartment equal to the sum of its two arguments. The next step is to sort the successes in order of their values, annexing to each the various grades of ability that have been associated with it, and to enter the averages of them at the side as in Table $V$.

TABIE IV.--Distribution of Successes, under the assumption that each differs little from that of the sum of its two variable constituents, and that these vary independently.

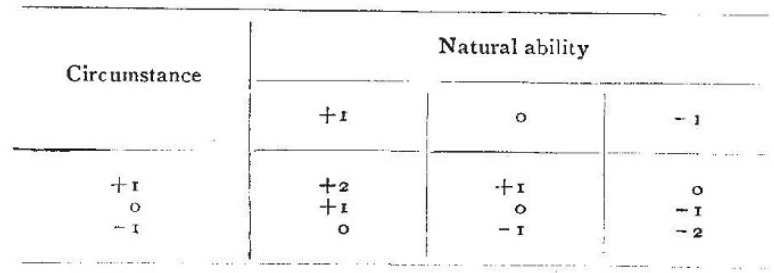

The entries in the body of the table represent the Successes. Each is the sum of its two arguments, which refer respectively to Natural Abilicy and to Circumstance.

TABLe V.-(Extracted from Table IV.)

\begin{tabular}{c|c|c|c|c}
\multirow{2}{*}{$\begin{array}{c}\text { Grades of } \\
\text { success }\end{array}$} & \multicolumn{4}{|c}{ Associated grades of natural ability } \\
\cline { 2 - 4 } & \multicolumn{3}{|c|}{ All of the observed values } & $\begin{array}{c}\text { Average } \\
\text { values }\end{array}$ \\
\hline & & & - & +1 \\
+2 & +1 & - & - & +1 \\
+1 & 0 & +1 & +1 & 0 \\
0 & -1 & 0 & -1 & $-\frac{1}{2}$ \\
-1 & -1 & - & - & -1 \\
-2 & -1 & - &
\end{tabular}

The result is that the average quantity of exceptional ability which is associated with any given amount of exceptional success is exactly its half. This same conclusion is reached by an a priori argument. Thus, let $\mathrm{S}, \mathrm{A}, \mathrm{C}$ be three independent variables, and $S=\frac{1}{2}(A+C)$. Then if $C$ be unknown, its average value will be mediocrity, that is, $=0$. Consequently $S$ will on the average be associated with $\frac{1}{2}(\mathrm{~A}+\mathrm{o})$, that is, with $\frac{1}{2} \mathrm{~A}$. There is a uniform rate of regression towards mediocrity. The same will take place if the cases are sorted in such proportions that the mediocrities shall be twice as numerous as either of the extreme groups. The table will then have four columns and four bands, with the arguments $+1,0,0,-1$, and it will have sixteen compartments. The result will still be the same if the mediocrities should be thrice as numerous as either of the extreme groups, and so on.

The two assumptions that have been made with the purpose of giving a rough idea of what would really occur must now be justified so far as may be. The first assumption was that natural ability and circumstance may be treated as independent variables. This position would be indefensible if we were making a precise analysis, because the two are certainly correlated to some extent. Thus a bright attractive boy receives more favour, and thereby has more opportunities of getting on in life, than a dull and unpleasing one, but these advantages are not unmixed with drawbacks attractiveness leads to social distractions, such as have ruined many promising careers. The amusing couplet of Henry Taylor is worth quoting :- " Me, God's mercy spared, from social snares with ease Saved by the gracious gift, ineptitude to please." Another instance of correlation is that the disposition to intellectual effort being heritable, a naturally studious boy is frequently brought up in a family whose influence and opportunities develop his natural bent; similarly as to natural scapegraces. But my returns here and elsewhere show that home influences are much less potent than might be supposed. Many correspondents speak of themselves as the only members of their family who had tastes like their own, and kinsfolk win distinction in many different directions. Moreover, a reaction against the monotony of home influences is often shown by those strong characters whose tastes are not in complete harmony with them. The correlation between natural aptitude and the circumstances favourable to success is consequently less strict than appears at first sight, and to the best of $m y$ judgment is not worth regarding in a rough inquiry.

The other assumption was that success is equal to the simple sum of natural ability and favouring circumstance. On the contrary, it must be some highly complex and discontinuous function of it. Still, the fact remains that a gifted child is more likely to succeed under conditions that are on the whole favourable to success than otherwise. The obvious objection that circumstances favourable to the development of one class of mind may be prejudicial to that of another is met by supposing a preliminary grouping of the men according to their dominant tendencies, scientific, scholastic, artistic, devotional, militant, and so forth, and treating these groups separately, each with its appiopriate classification of circumstance. Little more is asked for than that natural ability and circumstance, as reasonably interpreted, shall be considered cumulative, in a broad and general sense, in their power of leading to success. It follows from this that any "exceptionality" of natural ability will, on the average, be roughly proportional but inferior to the exceptionality of the accompanying success. Also that the two will agree in direction, good ability going with high success, poor ability with the reverse. Rare exceptions do not invalidate general conclusions, any more than the fact of one boy in a class of schoolmates dying very early or very late invalidates the expectation of life at school ages as calculated by actuaries.

Exceptionally Gifted Families.-The diagram would assure us, even if we had no other grounds for assurance, that exceptionally gifted families must exist, whose race is a valuable asset to the nation. A few of these have been indicated by the present returns; they well deserve, and will probably receive, a full description hereafter. It must suffice for the present to mention the existence of at least nine gifted families connected with fellows of the Royal Society, two or three of whom are exceptionally gifted. I will conclude with the remark that the experience gained through this inquiry has strongly confirmed an opinion expressed in my lecture on Eugenics before the Sociological Society, of which an abstract appeared in these columns (vol. lxx. p. 82), namely, that it would be both feasible and advantageous to make a register of gifted families. I have now better hope of being able to carry some such design into effect. 